\title{
Bernard Williams on the History of Ethical Views and Practices
}

\author{
TIM HEYSSE
}

How should we look back on the history and the origins of our ethical outlook and our way of life? We know that in the past, strange and appalling ethical views and practices have enjoyed widespread and sincere support. Yet we do not regard our contemporary outlook - to the extent that we do, at the present, have a common outlook - as one option among many. However bemused we may feel in ethical matters, at least on some issues we claim to have reasons that are good (enough). If we do not object to the use of the predicate 'true' in ethics, we may say that we are confronted with the (ethical) truth of an outlook. Or, to echo a provocative expression of David Wiggins, we claim that 'there is nothing else to think'. ${ }^{1}$

Given these features of our ethical life, it seems only natural to look upon our ethical outlook, and especially those aspects of which we feel certain and which differ from earlier outlooks, as the conclusion of a process of rational reflection. If our ancestors had thought thoroughly and sincerely enough, we tend to think, they would have arrived at an outlook similar to our own. At the very least, we imagine the history of ethical beliefs and practices to be a common cognitive enterprise, a common search for (ethical) truth to which consecutive generations have contributed.

According to Bernard Williams, this flattering representation of the history of ethics betrays an exaggerated idea of the rational justification of our outlook:

[...] a truthful historical account is likely to reveal a radical contingency in our current ethical conceptions. Not only might they have been different from what they are, but also the historical changes that brought them about are not obviously related to them in a way that vindicates them against possible rivals. This sense of contingency can seem to be in tension with something

1 See for instance David Wiggins, 'Objective and Subjective in Ethics, with Two Postscripts about Truth’ Ratio (New Series) VIII (1995), 244. 


\section{Tim Heysse}

that our ethical ideas themselves demand, a recognition of their authority. ${ }^{2}$

In accordance with this contingency of our ethical ideas, in two senses of the word, only a relativistic attitude is adequate with regard to ethical outlooks of the (distant) past. Williams's 'relativism of distance', summarized and applied to the past, is the thesis that in confrontations with past outlooks 'the language of appraisal - good, bad, right, wrong, and so on $-[\ldots]$ is seen as inappropriate, and no judgments are made'. ${ }^{3}$ Such appraisals cannot be vindicated and therefore amount to nothing more than an empty compliment to ourselves. ${ }^{4}$ The past must not be judged; it must be studied and interpreted. ${ }^{5}$

Issues about relativism typically concern the rational status of our evaluations (their 'vindication'). Since Williams's version of ethical relativism is no exception, I will criticize his objections to appraisal of ethical outlooks from the past. However, the prime focus of this paper is not on the epistemological issues of rational status, but rather on the question of how we should conceive of the history of ethical views and practices and of our place in that history. Although relativism of distance is not meant to pertain solely to past outlooks, I will only consider it as such. At any rate, it is

2 Truth Eீ Truthfulness: An Essay in Genealogy (Princeton and Oxford: Princeton University Press, 2002), 20. Compare Ethics and the Limits of Philosophy (ELP) (London: Fontana Press/Collins, 1985), 16, 'Philosophy as a Humanistic Discipline. The Annual Lecture of the Royal Institute of Philosophy' Philosophy 75 (2000), 489-490; 'Ethics and the fabric of the world' (1985), in Making sense of humanity and other philosophical paper 1982-1993 (Cambridge: Cambridge University Press), 179-180; 'Pluralism, Community and Left Wittgensteinianism' (1992), in In the Beginning Was the Deed. Realism and Moralism in Political Argument (Princeton and Oxford: Princeton University Press, 2005), 36.

3 ELP, 161; 'The Truth in Relativism' (TIR) (1974-75), in Moral Luck. (Cambridge: Cambridge University Press), 142-143. Judgments concerning past conceptions of social justice is the one exception Williams is prepared to make, cf. ELP, 165-166; 'Human Rights and Relativism' in In the Beginning Was the Deed, op. cit. n. 2, 69.

4 ELP, 159-160; 'Philosophy', op cit. n. 2, 488.

5 Compare 'Saint-Just's illusion' (1982), in Making sense of humanity, op. cit. n. 2, 146. Williams suggest that relativism of distance only applies to "fairly large scale systems or bodies of beliefs"; ELP, 162, 69, "Human Rights', op. cit. n. 3, 69. Yet ethical judgments concerning individual people and their actions appear to suffer in the final analysis from similar defects as more general assessments, ELP, 162; cf. TIR, 141-142. 


\section{Bernard Williams on the History of Ethics}

especially vivid and plausible when recommending a relativist attitude towards past views and practices. ${ }^{6}$

Focusing on our relationship with the past is not to deny that relativism of distance is one 'of the three most important and best known aspects of Williams's views on the nature and possibility of knowledge and objectivity in the realms of science and ethics' ${ }^{7}$ - views that are in turn closely connected to his internalist interpretation of practical reason. ${ }^{8}$ Relativism of distance can only be understood by situating it within the wider context of Williams's more general meta-ethical ideas ${ }^{9}$ (section 1). Indeed, although Williams's internalism and his other meta-ethical views do not, on their own, impose relativism of distance (as I will argue in section 2), they do challenge an assumption implicit in the Whig interpretation of the history of ethics sketched in the opening paragraphs of this paper, in effect paving the way for relativism of distance. By discussing (in section 3) Williams's ideas on interpretation (that have, surprisingly enough, not drawn the attention of those of his critics to whom they were available) ${ }^{10}$, I will explain the importance of ethical appraisal of past outlooks. In this manner, I hope to shed some light on the question as to how we can look back upon the history of our ethical beliefs and practices (section 4).

6 See also Samuel Scheffler, 'Morality Through Thick and Thin. A Critical Notice of Ethics and the Limits of Philosophy', The Philosophical Review XCVI (1987), 427-428; Mark P. Jenkins, Bernard Williams (Chesham: Acumen, 2006), 142.

Jenkins, op. cit, n. 6, 124.

8 Compare Martin Hollis, 'The shape of a life' in J.E.J. Altham and Ross Harrison ed., World, Mind, and Ethics. Essays on the ethical philosophy of Bernard Williams (Cambridge: Cambridge University Press, 1995), 173. Internalism is the starting point of much of the discussion in ELP, in particular of the rejection of 'ethical theories'.

9 This contrasts with recent work where a more isolated discussion of Williams' relativism of distance is to be found, see e.g. Carol Rovane, 'Did Williams find the truth in relativism?' in Daniel Callcut ed., Reading Bernard Williams (Abingdon/New York: Routledge, 2009); Maria Baghramian, Relativism (London and New York: Routledge, 2004).

10 See for instance, Jenkins, op. cit. n. 6, 139-140. Putnam appears to endorse Williams' views on interpretation, see Hilary Putnam, 'Objectivity and the Science/Ethics Distinction' in James Conant ed., Realism with a Human Face (Cambridge, Mass: Harvard University Press, 1990), 167-168. 


\section{Tim Heysse}

\section{A sense of history}

Perhaps we can agree that all ethical reflection is concerned with what Williams has famously called 'Socrates' question'; every ethically reflective person may be viewed as seeking an answer and every properly reflective ethical outlook as providing the answer to the timeless question, 'how one has most reason to live', or what are 'the conditions of the good life' ${ }^{11}$ However, an accurate analysis of the question demonstrates its perfectly general nature. As a matter of fact, Socrates' question as understood by Williams, is not even a specifically ethical question: 'If ethical reasons [...] emerge importantly in the answer, that will not be because they have simply been selected for by the question.' 'The question may be called 'timeless', but not because the same question persists trough the ages, but rather because 'it invites me to think about my life from no particular point in it'. ${ }^{12}$ If it is indeed 'anybody's question' and if 'the question can be put to anybody', it remains for Williams at the beginning of Ethics and the Limits of Philosophy very much an open issue to what extent "the question asked by anybody "how should I live" can simply be equated to 'the question how should anybody live'. ${ }^{13}$

It is precisely against the identity of Socrates's question with the question 'how should anybody live' that an internalist interpretation of practical reason argues. As a matter of fact, on an internalist interpretation of practical reason, practical reasons are internal reasons; 'A has most reason to $\phi$ ', means that there is 'a sound deliberative route to $\phi$-ing which starts from A's existing motivations'; or, at the very least, it 'should say something special about $\mathrm{A}$, and not merely invoke in connection with him some general normative judgments'. ${ }^{14}$ Applied to reason-statements in ethics, this implies that ethical considerations give a reason to act 'only if they are related to other reasons for actions, and generally to [...] desires, needs and projects' ${ }^{15}$

11 This is the interpretation of the question that Williams ultimately deems acceptable, ELP, 6; cf. Morality. An Introduction to Ethics (Cambridge: Cambridge University Press, 1972), 73-81.

$12 \quad E L P, 19$.

13 ELP, 20-21, cf. 3.

14 'Replies' in Ross Harrison and J.E.J. Altham ed., op. cit. n. 8, 186 and 191-192. For the purposes of this paper, a more exact formulation of Williams internalism is unnecessary, cf. Joshua Gert, 'Williams on reasons and rationality' in Daniel Callcut ed., op cit. n. 9.

15 'Preface to the Canto Edition' in Morality. An Introduction to Ethics (Cambridge: Cambridge University Press, 1993), XIII. 


\section{Bernard Williams on the History of Ethics}

The vital issue for Williams is therefore not the truth of ethical utterances but rather 'the value of truth'. ${ }^{16}$ The divergence between ethical outlooks need not be a matter of differing truthvalues but rather of the value we attach to the truth of ethical statements. This is particularly clear in the study of past outlooks, as this confronts us with alien or obsolete ethical concepts we do not normally use ourselves. ${ }^{17}$ (Williams's most favoured example of such an obsolete concept is 'chaste', but we can easily imagine others such as 'pure/impure' or 'human sacrifice'.) During a confrontation with such a concept, 'an insightful observer can indeed come to understand and anticipate the use of the concept without actually sharing the values of the people who use it'. ${ }^{18}$ Although we have learned under what conditions sentences built with the concept are true (we have learned the extension of 'is chaste'), we see no reasons to structure our experience, our judgments and our lives by virtue of that concept's application.

Obviously, this different appreciation of the ethical point of some of the concepts we learn, although not necessarily apparent in the truth-values of the sentences built with these concepts, will reappear in the truth-values of other (second-order) sentences, such as 'Whether $\mathrm{X}$ is chaste is ethically important' or ' $\mathrm{X}$, being chaste, is part of a life that I have most reason to live'. However, that is not to deny Williams's interesting point that ethical reflection is above all a search for the truths with which we are willing to live ${ }^{19}$; it is a search for self-knowledge. The primary concern is to know who you are, or, in the words of D.H. Lawrence quoted by Williams with approval, to find 'your deepest impulse and follow that'. ${ }^{20}$

16 'Truth in Ethics' ('TIE) Ratio (New Series) VIII (1995), 230, 232. Although in ELP he argues that using so-called 'thin' ethical concepts such as 'morally right' or 'morally acceptable' we cannot formulate knowledge in the sense of "a body of propositional knowledge of ethical truths", Williams is prepared, in later work, to predicate truth of ethical statements, cf. TIE, 227-229; 'Who needs ethical knowledge?' (1992), in Making sense of humanity, op. cit. n. 2, 211, n. 2.

17 Note that the point made in the text does not presuppose that there is a clear distinction between 'thick' and 'thin concepts', Scheffler, op. cit. n. 6, 414-417.

18 ELP, 142.

19 'Internal reasons and the obscurity of blame' (1989) in Making sense of humanity op. cit n. 2, 37-38; cf. TIE, 236, 237; 'Pluralism, Community and Left Wittgensteinianism' (1992), in In the Beginning Was the Deed, op. cit. n. 2, 36 . 


\section{Tim Heysse}

Accordingly, the 'only intelligible form of ethical objectivity' for Williams would derive from scientific knowledge about what human beings need in order to lead a happy life or, at least, to function normally (for instance information about basic natural needs and motivations). ${ }^{21}$ For guidelines about how to be happy or to live normally (assuming that they do not depend on further valuejudgments) may well constitute, like health instructions, internal reasons. ${ }^{22}$ Considerations relating to what all human beings 'at some level' want - such as health or happiness - explain what a particular person wants, while still applying to everyone. The resulting ethical outlook would be internalist but also universalist and objectively justified. However, since this is, even to Williams himself, nothing but a barely conceivable possibility still far from being realized, our actual ethical outlook is 'one of many that are equally compatible with human nature'. ${ }^{23}$

Consequently, it is unclear what claim we are exactly making when we say, in relation to some ethical issue or other, that there is nothing else to think:

There is always more than one true thing to think about any situation. What "there is nothing else to think but that p", must mean is, there is nothing else to think given the question whether $p$. This relativises the claim to those who use the concepts involved in the question whether $p \cdot{ }^{24}$

If different ethical concepts were used in the past and if there is no vindication for using a particular set of concepts (our own, for example), we cannot even assume that people in earlier times were trying to answer the same questions.

What is challenged by these meta-ethical views is not the importance of Socrates' question, but the idea that it is in fact one question, an identical question eliciting the same solution throughout history, conceivably to be implemented variously in different circumstances.

20 See Williams, Morality, op. cit. n. 11, 79; cf. Williams's remark taken down in Jeffries, Stuart 2002: 'The quest for truth' - http://books/guardian.co.uk/review/story/01,12084,850062,00.html. and Susan Mendus, 'Making Sense of Our Lives' Politicial Studies Review 5 (2007), 366.

21 ELP, 51-53, 44-45, 152-155. Cf. 'Saint Just', op cit. n. 5, 141-149; 'Philosophy', op cit. n. 3, 249.

22 'Internal and external reasons' (1980) in Moral Luck, op. cit. n. 3, 105-106. For the extension to functioning normally and being happy, see ELP, 40-43.

$23 \quad$ ELP, 147.

24 TIE, 237; cf. 'Ethical knowledge', op. cit. n. 16, 212, n. 6. 


\section{Bernard Williams on the History of Ethics}

In other words, what is challenged is the assumption that every ethically reflective person is 'at some level' groping for answers to the same questions, that all people, whatever period of history to which they belong, have, to the extent and by the very fact that they are involved in ethical reflection, similar concerns. One of the merits of Williams's relativism is certainly the fact that he draws attention to the undeniable differences between our own concerns and social circumstances and those of people in earlier times. He rightly wants to maintain a view of the past as 'a concrete historical reality', preserving it from the 'historical fantasy' that attends so much ethical appraisal of the past. ${ }^{25}$

Furthermore, since most criticisms of relativism of distance were formulated as part of a more wide-ranging criticism of Williams's general meta-ethics, they are naturally read, in addition to making their fundamental meta-ethical points, as rebutting Williams's challenge to the assumption of a cognitive enterprise common to all ethically reflective persons. ${ }^{26}$ Williams's opponents may have good reasons for arguing that relativism of distance depends on 1) the 'unwarranted' suggestion that judging the past 'would be insensitively parochial', 2) ignores the possibility that making judgments 'can be the upshot of a kind of reflection which encompasses the possibility of learning from conflicting outlooks', and 3) is threatened by incoherence, since it requires us to 'combine recognizing the

TIR, 141.

This applies even for more specific objections that depend on the particulars of the past outlook that is being judged, such as Putnam's observation that many ethical views cannot be disentangled from views about the world that according to Williams's own views on objectivity are open to scientific criticism, Putnam, op. cit. n. 10, 175; cf. Jenkins op. cit. n. 6, 144-145 or the question, put by Meitland and Mendus, why we should suspend our judgment on social systems or ways of life of the past, whereas Williams agrees, as I will explain in section 2, that we can and must judge them if they continue into the present, cf. Jack W. Meiland, 'Bernard Williams' Relativism' Mind 88 (1979), 261; Mendus op. cit. n. 20, 373. Other recent critics are even more outspoken in identifying the question of a common ethical enterprise as the main issue in the debate with relativism of distance, cf. Rovane, op. cit. n. 9 and her opposition between 'unimundialism' and 'multimundalism' and John Cottingham, 'The good life and the "radical contingency of the ethical"' in Daniel Callcut ed., op. cit. n. 9, 31: 'we can contemplate the fascinating variety in human cultures and ethical systems yet at the same time see all or many of them, in their different ways, as satisfying or approaching the conditions for human fulfilment.' 


\section{Tim Heysse}

conflict and standing by one's own outlook with disclaiming any interest or even possibility of making some negative assessment of the other?' 27 By rejecting the charge of parochialism supposedly attached to evaluating the past and emphasizing what there is to learn from past outlooks and what our commitments to our own outlook entail for appraisal of the past, however, these criticisms, implicitly if not quite openly, deny the distances that, in Williams's view, separate us from the past. Particularly when considered in the context of a general discussion of his meta-ethics, these objections to Williams's relativism of distance are so many ways of saying that all ethically reflective persons share ethical concerns and questions.

To conclude, the debate on Williams's relativism of distance appears to turn on the issue of whether we have a theoretical or meta-ethical justification for claiming that all ethically reflective persons are concerned with the same ethical truths and are in a sense trying to answer the same ethical questions. And if that is the main issue, Williams and his opponents appear to share the assumption that appraisal of the past is only appropriate or genuine provided that we can give real content to the idea of a common cognitive enterprise, if we can show that history, considered as a search for (ethical) truth, is actually a search for an answer to an unchanging question.

The problem is of course that this assumption is doubly incompatible with a full recognition of history. Naturally, the notion of a cognitive enterprise shared by all ethically reflective persons denies the differences between past and present. Moreover, requiring that such appraisal of the past be conducted in the light of a question that is shared by outlooks of all ages suggests that appraisal of the past is only acceptable if it derives from an evaluation that is not motivated by questions or concerns particular to a specific period in history. It must, in other words, be derived from an evaluation that, in this sense, 'stands above history'. If we assume that appraisal of the past requires the identification of a common question that all people throughout history were trying to answer, appraisal of the past is indeed irreconcilable with a proper sense of history.

It is this assumption I shall endeavour to contest in the remainder of this paper. Taking Williams's general meta-ethical views for granted (thereby bracketing the idea of a common cognitive enterprise), I will explain the justification and the ethical significance of evaluating past outlooks. I shall thereby propose an interpretation and the Limits of Philosophy by Bernard Williams' Mind XCV (1986), 384; for similar criticisms see Putnam, op. cit. n. 10, 177, 105. 
of the history of ethical outlooks without any suggestion of a cognitive enterprise common to all of history.

\section{Relativism of distance}

One remarkable point about Williams's relativism of distance is that he distinguishes acceptable from unacceptable versions of relativism $^{28}$ and rejects more ordinary formulations of relativism. Relativism of distance does not pertain to conflicts in the contemporary world, nor to 'real' confrontations, but only to 'notional' confrontations. A confrontation is 'real' (as opposed to 'notional') in Williams' terminology if we could, after deliberation from our existing motivations and without succumbing to delusion, go over to the alternative outlook with which we are confronted. Arguably, past forms of life ("the life of a Bronze Age Chief or a medieval samurai') cannot be anything but notional alternatives, alternatives too far removed from our own concerns and situation to be genuine contenders for adoption. There is not only our dependence on technology undreamed of in the past. More important to Williams is 'the peculiar level of reflectiveness' marking the modern word and the fact 'that there is no route back from reflectiveness [...], no way in which we can consciously take ourselves back from it'. ${ }^{29}$ Accordingly, relativism of distance applies in particular to outlooks of the past.

Given that Williams's meta-ethical views do not lead to relativism in more ordinary (or 'real') confrontations, but only in notional confrontations, the justification of relativism of distance requires extra premises in addition to these meta-ethical views, clarifying why relativism is called for in the one case and not the other. Williams's work contains two interlocking but different arguments in favour of a relativist attitude towards the past.

A first line of reasoning begins with the fact that, apart from scientific knowledge of basic human needs and motivations, no objective

Meiland, op. cit. n. 26, 258-259; Jeremy Waldron, 'How to argue for a universal claim' Columbia Human Rights Law Review 30 (1998-1999), 308.

ELP, 163-164; cf. Ibid.: 'Today all confrontations between cultures must be real confrontations'. This last point also clarifies that what distinguishes real from notional confrontations is not well put in terms of 'adopting' or 'going over to' the alternative outlook; even if we cannot envisage 'going over' to a particular present-day outlook, confrontation with that outlook is not notional, because we share with its supporters the concern of having to live on the same shrinking planet. 


\section{Tim Heysse}

justification is to be expected in ethics. Although we may spontaneously react with revolt or indignation when we learn of practices or views espoused in the past, we should suspend, because of the lack of such justification, the negative ethical judgments explicitly expressed or implicitly manifested in such spontaneous emotional reactions. ${ }^{30}$ As we do not have, in a confrontation with a real alternative or in a situation in which some reaction is required, any objective justification either ${ }^{31}$, the difference between confrontations in the present and those with past outlooks cannot be the mere lack of vindication. It is not difficult to see where the important difference does in fact lie. Since the only intelligible notion of objectivity in ethics consists in scientific knowledge of needs and motivations common to all people and since past outlooks are merely notional alternatives to our own outlook (they are 'related to our concerns too distantly' 32 ), the lack of objective justification and the absence of information on universal needs and motivations imply that our outlook and the judgment of the past inspired by it depend on interests or concerns that are not shared by supporters of the past outlook. Williams objects to ethical judgments of past outlooks, because such judgments do not rest on concerns that we can realistically ascribe to the supporters of these outlooks. ${ }^{33}$ They have no additional content over and above affirming our own outlook, 'simply saying that we are right and everyone else is wrong'. ${ }^{34}$

Williams' second objection to appraisal of the past derives from the obvious fact that during contemporary conflicts demanding a reaction or confrontations with real alternatives, the question arises what to do (how to react, whether to adopt the alternative), whereas in the case of a notional confrontation with a past outlook no such practical question arises: 'the past is not another country: if it were

$30 \quad E L P, 159-160$.

31 Scheffler, op. cit. n. 6, 428. Scheffler makes the point for justice.

32 TIR, 142.

33 This interpretation is confirmed by the fact that questions of justice or injustice of past societies are immune to the relativism of distance, since 'some conceptions of justice were used in those societies themselves', $E L P, 166$; for related thoughts see TIE, 234; 'Saint Just', op. cit. n. 5, 137; 'Human Rights', op. cit. n. 3, 69; 'Realism and Moralism in Political Theory' in In the Beginning Was the Deed, op. cit. n. 2, 3-6; cf. also Scheffler, op. cit. n. 6, 428. We encounter an analogous thought in Chapter 7 of Truth $\sigma^{\circ}$ Truthfulness, op. cit. n. 2, where the discovery of history is portrayed as 'an intellectual advance', because it satisfied intellectual needs in a sense already present earlier, see especially 170.

34 ELP, 159-160. 


\section{Bernard Williams on the History of Ethics}

just another country, we might have to wonder what to do about it'. ${ }^{35}$ As, consequently, no practical problem arises, 'the question of appraisal does not genuinely arise'. ${ }^{36}$ The past, by definition 'not within our causal range' 37 , is for that very reason also beyond the competence of our ethical judgment.

In short, Williams argues that appraisal of the past does not satisfy two conditions for genuine ethical judgment. For 1) we cannot claim that our judgment and the outlook supporting it are inspired by interests or concerns that people in the past could have recognized, nor 2) does appraisal of the past concern a practical question about what to do.

Clearly, the second of these conditions characterizes an undeniable aspect of our relationship with the past; and so does the first, at least for supporters of Williams's internalism as summarized above. Both conditions accentuate the distance between ourselves and the past and are tantamount to a very sensible, if rather obvious methodological guideline: in appraising past outlooks and in recording the reasons our predecessors had for adopting their way of life, we must guard against anachronistic representations of their situations and concerns.

What is much more questionable is the claim that these requirements indeed express conditions of genuine ethical appraisal. As far as I know, Williams does not argue for that claim. What's more, imposing the second condition seems to be in contradiction with his idea that ethical reflection is concerned with acquiring self-knowledge. To be sure, getting to know ourselves will influence our deliberations about practical questions and trying to imagine how we would react in a given situation may contribute to self-knowledge. Nevertheless ethical significance is not thereby reduced to what is directly relevant to practical deliberation. Moreover, it seems implausible that such emotions as admiration or loathing are not part of the ethical as it is commonly conceived. Since reasons to feel (even reasons to feel admiration or loathing) need not be reasons to act, ethical reflection encompasses other issues beside practical ones about what to do.

The first condition, the claim that ethical judgment requires a foundation in interests or concerns that can be ascribed to those being judged, does not immediately follow from Williams's internalist

35 'Human Rights', op. cit. n. 3, 69; cf. Meiland, op. cit. n. 26, 260 discovers a similar argument in TIR but he does not formulate it quite so generally.

36 TIR, 141, 142; 'Philosophy', op cit. n. 3, 491.

37

Ibid. 


\section{Tim Heysse}

interpretation of practical reason. For internalism does not preclude criticism of people who do not share the ethical concerns that inspired the criticism. As Williams himself points out, internalism does not require us, for instance, to spare amoral persons from criticism who remain deaf to ethical considerations. It merely implies that to say that they have a reason to behave differently does not add anything significant to the ethical disapproval we have already expressed. ${ }^{38}$

As already explained above, the most that appears to follow from Williams's internalism is that judgments claiming to refer to a foundation or principle that we share with the past are out of place. To the extent that judgments expressed with 'thin' ethical terms do refer to such a common moral foundation, supporters of Williams's internalism should avoid using these terms in speaking of the past. However, and obviously, many other things can be said. For instance, that the people of earlier times have overlooked something that we think is ethically relevant, that they missed an opportunity to be generous or merciful, that they showed insufficient respect for a particular person or value.

\section{Interpretation}

If we turn our attention from the motivations and concerns of earlier people to our interest in the past, we discover that some of Williams's views with regard to interpretation are far from plausible. ${ }^{39}$ Correcting these views, we will be able to show that confrontation with the past may be of ethical importance. (Since, Williams's analysis of interpretation does not apply directly to the interpretation of past outlooks, I will first formulate my objections to the analysis itself and then go on to explain their implications for confrontations with past outlooks.)

In order to denounce the fiction that 'there is an homogenous class of ethical assertions', Williams considers the situation of an interpreter learning a language $\mathrm{L}$ containing unfamiliar ethical concepts. If successful, the interpreter will become a competent user of those concepts; 'there are whole days perhaps in which his world is the world of the L-speaker'. However, what he cannot do, in Williams's view, is translate the concept into his own language. Or, more technically,

38 'Replies', op. cit. n. 10, 190-191; 'Obscurity of blame', op. cit. n. 19, 39-40; ELP, 192.

39 Compare Jenkins, op. cit. n. 6, 146. But Jenkins does not elaborate. 


\section{Bernard Williams on the History of Ethics}

What he can't do is to generate a Tarski-equivalent right hand side in his own language $\mathrm{L}_{\mathrm{o}}$ for the claim that (e.g.) " $\mathrm{X}$ is chaste" is true in $\mathrm{L}$. The reason he can't do this is that [...] the expressive powers of his own language are different from those of the native language precisely in the respect that the native language contains an ethical concept which his doesn't. If [...] his ethical language is based largely on thin ethical concepts, you might say the expressive powers of his language are weaker $[\ldots]^{40}$

What is striking in this quotation is the remarkably static, a-historic conception of a language, as if a language is a fixed store of concepts. Williams does not seem to consider the eventuality that the language of the interpreter might change. For why else is the interpreter unable to say what the speaker is saying? ${ }^{41}$ If the interpreter learns a novel ethical concept and reflects on its ethical point, he may come to appreciate that point; he may realize that speakers of $\mathrm{L}$ are pointing by means of the concept to something ethically significant - significant for the interpreter himself, to be adopted as part of his life at home. In short, the interpreter, learning something ethically significant in actual practice, acquires a new concept (as a truly ethical concept). ${ }^{42}$ Similarly, an interpreter whose "language is based largely on thin ethical concepts' may for example learn the difference between cruelty and brutality ${ }^{43}$ and find out how to differentiate by means of these 'thick' concepts between actions that he used to call 'morally unacceptable' indiscriminately. To be sure, the result in both cases will be that the interpreter's language is not exactly 'our' language any longer. It is not the language he and we who have stayed at home used to share. His language has been enriched by his interactions with the speakers of L.

Keeping this more dynamic conception of language in mind, let us review the situation of an interpreter learning a concept the ethical point of which he understands but cannot share. In contrast to the case described in the previous paragraph, the interpreter decides

40

TIE, 239.

41 ELP, 143-144, advances another argument in favour of this conclusion, convincingly refuted in A.W. Moore, 'Can Reflection Destroy Knowledge?' Ratio (New Series) IV (1991) and Warren Quinn, 'Reflection and the loss of moral knowledge. Williams on objectivity' (1987) in Morality and Action. Edited by Philippa Foot (Cambridge: Cambridge University Press, 1993).

42 As Williams knows, of course, TIE, 237; but he does not seem to take it into account.

$43 E L P, 14$. 


\section{Tim Heysse}

not to use the concept and therefore chooses not to include it in his language, as he would have done were he convinced of the ethical relevance of the concept. In other words, by not accepting a concept as one of his own, he has come to an (implicit) judgment on its relevance. Interpreting an outlook (grasping its meaning) and judging it (appraising its ethical meaning) are inextricably intertwined: we discover its significance by defining our position towards it.

As already stated, we are not discussing confrontations here with notional alternatives or confrontations with outlooks of the past. For Williams envisages the situation of an interpreter who, although unable to translate foreign ethical concepts, is perfectly capable of living in both cultures. And my objection turns on the fact that an interpreter cannot avoid the question as to whether an unfamiliar concept points to something ethically significant for him, for his own life. Since every past outlook is a notional alternative, it follows that such a situation and such a question will never arise with regard to concepts that are part of a past outlook. If judging or appraising the past means deciding whether or not to take statements built with concepts of the past as a guide in our lives and deliberations about what to $d o$, it might be trivially true that we cannot judge the past.

Because practical decisions are not called for, the situation of an interpreter studying an outlook from the past differs radically from that of an interpreter confronted with a real alternative. ${ }^{44}$ Nevertheless, the interpretation of the past is sufficiently analogous to interpreting a real alternative so as to be justified in claiming that an interpreter of a past outlook cannot avoid the appraisal of the past outlook either. For one thing, the fact that concepts of the past cannot guide us in our actions does not mean that the past is - ethically speaking - indifferent to us. As already mentioned, confrontation with the past can arouse strong emotional reactions of condemnation or endorsement, of sympathy or dislike. Noting that Williams does not really present arguments for his claim that ethical reflection is limited to practical questions, we need not feel that we should suspend the judgment implicit in or connected to these emotional reactions. It remains a very real question what we are, from an ethical point of view, to think about the past.

However, the analogy is even closer. An outlook of the past, even if we cannot live with it, may still have an impact on our own ethical outlook. For instance, we may discover that people of the past

44 Given that my analysis does not in any way minimize the distinction between real alternatives and merely notional alternatives, it cannot be discarded as an instance of what TIR, 142-143 calls 'the evaporating view'. 


\section{Bernard Williams on the History of Ethics}

displayed a form of ethical wisdom now lost to us. We may come to realize that we are overlooking something ethically important that was understood in the past. This kind of eye-opening experience is possible, even if the ethical wisdom of the past is, for us, unrepeatable or inaccessible, even if we cannot any longer integrate it in the kind of lives we now lead. ${ }^{45}$

For instance, hearing of certain invasive policies undermining a way of life going back for centuries or of megalomanic construction plans threatening the urban fabric of ancient cities, we may feel that what is objectionable in these policies and plans is not merely, as the case may be, their stupidity or inefficiency, the greed or lust for power motivating them. It may also be the fact that they transgress certain limits of human action by intending to destroy in one generation what has been built over centuries. In those situations we may begin to appreciate the wisdom of a certain 'ethics of measure' current in antiquity and in the Middle Ages. This appreciation is perfectly compatible with recognizing that the cosmology upon which this ethics of measure was based, is no longer plausible or even with an acknowledgment that we owe many valuable aspects of our modern culture to transgressions of that ethic. Whatever may be forwarded in objection to this attitude, it does not seem obviously incoherent.

Nor is it merely a theoretical or conceptual possibility, as illustrated by an actual example, the famous lecture on 'The liberty of the Ancients Compared with that of the Moderns' by the $19^{\text {th }}$ century French politician and political thinker, Benjamin Constant. Constant is certainly not blind to the morally dubious aspects of ancient society (such as slavery and its 'bellicose spirit'). He glorifies 'progress and enlightenment' for having emancipated us from those evils and 'mistrusts' spurious 'admiration for certain ancient memories'. ${ }^{46}$ In particular, he points to the 'infinite evils during [the]

45 The importance of these experiences of an unrepeatable or inaccessible excellence was pointed out to me by Arnold Burms. One of his most telling examples comes from the history of art: we admire the greatness of past masters, while acknowledging that it would be plain silly (if not criminal) for us to try and paint exactly as they did. I do not think that Williams does justice to this kind of experiences in the ethical case when he disposes of them as 'ethical stories we tell about the past or the exotic [that] have little to do with the reality of those times or places. [...] They do not really think about other societies, but use them as a source of emblems or aspirations', ELP, 162-163.

46 Benjamin Constant, 'The Liberty of the Ancients Compared with that of the Moderns' (1819), in Political Writings. 'Translated and Edited by Biancamaria Fontana (Cambridge: Cambridge University Press, 1988), 322. 


\section{Tim Heysse}

long and stormy' Revolution in France, in effect inspired by philosophers who 'failed to recognize the changes brought by two thousand years in the disposition of mankind' ${ }^{47}$ As a result of these changes, ancient views on liberty are 'no longer valid'. ${ }^{48}$ Nevertheless, there is no doubt in Constant's mind that the historical evolution which makes the 'liberty of the ancients' obsolete and therefore undesirable constitutes 'a loss'; a loss, moreover, 'that is difficult not to regret':

We can no longer enjoy the liberty of the ancients, which consisted in an active and constant participation in collective power. Our freedom must consist of peaceful enjoyment and private independence. The share which in antiquity everyone held in national sovereignty was by no means an abstract presumption. [...] Everybody, feeling with pride all that his suffrage was worth, found in this awareness of his persona importance a great compensation. ${ }^{49}$

Moreover, contemplation of this old notion of liberty, however outdated, elucidates important aspects of political life that we ignore at our peril.

Our acknowledgment of such an inaccessible wisdom may be indicated by adopting an alien or restoring an obsolete concept (such as 'liberty of the ancients'). We include the alien or obsolete concept in our language without knowing how we might take guidance from statements framed with this concept in our lives and in deliberations about what to do. In this manner, our outlook and our ethical language may grow richer because of confrontations with the past. If, on the other hand, we conclude that the alien or obsolete concepts do not indicate anything of ethical importance to us, we decide not to include them in our language. Trying to understand an outlook of the past therefore requires ethical appraisal in a way that is similar to what, according to my comment on Williams's analysis, is presupposed by a confrontation with a real alternative.

Williams's static conception of language prevents him from realizing that the interpretation of past outlooks inevitably involves what I persist in calling an appraisal of their ethical relevance. It is precisely because Williams erroneously distinguishes between interpreting and appraising or judging that the question arises on what grounds we may base our appraisal of past outlooks. Once this question is in the air and

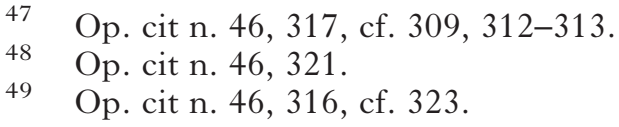




\section{Bernard Williams on the History of Ethics}

assuming that we try to avoid the notion of a common enterprise in ethics, the conclusion seems tempting that there are no such grounds.

It is important to note that my argumentation does not require any general theoretical or meta-ethical doctrine about the existence or non-existence of a cognitive enterprise common to all ethically reflective persons throughout history. For instance, my argumentation, although it does begin with considerations about interpretation, should not be confused with an argument to the effect that Donald Davidson's analysis of radical interpretation and his identification of a principle of charity indicate the existence of a common human nature that might constitute the foundation of a universalistic ethics. Against this argument, Williams raises the very convincing objection that our knowledge of this common human nature, assuming we will be able to acquire it in this way, will probably be far too general to establish a usable ethics. ${ }^{50}$ My criticism of Williams's account of interpretation does not refer to any notion of a common human nature.

To the extent that we endorse Williams's internalism, we must acknowledge that our appraisal of the past is not based on anything but our own outlook. In this sense, Williams is right in claiming that our appraisal does not add anything to the affirmation of our own outlook. However, we must avoid a static understanding of this claim: what we are affirming is our own outlook as it has come about in confrontation with the past. Accordingly, we cannot ignore the ethical significance of such confrontations.

\section{Conclusion: the history of ethics as a search for truth}

There is no denying the hypothetical nature of this essay. After all, I started out by simply adopting Williams's internalism. Internalism may prove to be untenable; an acceptable account may one day be given of the claim that all ethically reflective persons share common concerns and questions. However, for the purposes of this paper, it has been useful to take internalism as a starting point, since it allowed us to set to one side the idea that appraisal of the past requires the identification of such a common cognitive enterprise. Rather than justifying appraisal of the past by a general meta-ethical doctrine about questions or concerns common to all ethically reflective persons, we have pointed to the experience of discovering new ethical questions or considerations as a consequence of the

'Saint Just', op. cit. n. 5, 141-142, 149-150. 


\section{Tim Heysse}

confrontation with the past, an experience that may be signalled by incorporating or reinstating an alien or obsolete concept into our language

What is more, having unambiguously set to one side the notion of a common cognitive enterprise (in other words, having bracketed the interpretation of the expression 'a search of truth' in terms of a search for answers common to all ethical persons or outlooks) and having rehabilitated the notion of an appraisal of the past, we may discover a different sense in which the history of ethical views and practices can once more be understood as 'a search for truth'. In contrast to the idea of a common cognitive enterprise, this alternative interpretation does not have the disadvantage of being difficult to reconcile with a proper sense of history.

In order to understand this alternative interpretation of the history of ethical views and practices as a search for truth, we must merely consider the following points. (1) As argued in the previous section, studying the past does not only involve learning unfamiliar concepts (such as 'liberty of the ancients') and unfamiliar truths built with these concepts (such as 'Doing $\mathrm{X}$ is compatible with the liberty of the ancients'). In so doing we cannot avoid the judgment as to whether these concepts and truths have something to tell us that is ethically significant, even though it is not something that has practical consequences nor anything that we can integrate in the kind of lives we now lead. In this sense, we inevitably evaluate outlooks of the past on the basis of their contribution to our outlook: that is to say, our present outlook as it has come about during the confrontation with the past. In other words, our rehabilitation of appraisal of past outlooks does not contradict in any way Williams's thesis that all confrontations with past outlooks are notional.

(2) Obviously, this judgment on the contribution of a past outlooks to our own outlook may be expressed as a true-apt statement, for instance as a (second-order) truth about the importance of certain truths suggested by the outlook of the past (such as truths about the liberty of the ancients). Granted that confrontation with past outlooks has an impact on our own ethical outlook, we may assume, moreover, that we study the past with exemplary historical scholarship, using all the skills and techniques historians have acquired in their attempts to reconstruct earlier periods and that, in our appraisal of the past, we strive for sincerity, fairness and accuracy. In the positive case where we learn something ethically significant from the past, we could say that the outlook from the past anticipated a truth that we ourselves accept (even if we have learned it only as a consequence of learning about the outlook of the past). In this sense, we may evaluate 


\section{Bernard Williams on the History of Ethics}

outlooks of the past by determining their adherence to what we claim to be (part of) the ethical truth.

(3) This attitude need not be limited to a confrontation with a single outlook; it can be generalized. Studying the history of ethical views and practices we may order developments within and the succession of ethical outlooks from the point of view of their including ethical points that we ourselves (have learned to) appreciate. We could say that we order different views and practices from the point of view of their contribution to our ethical outlook, as it comes about during the study of history; that is to say, their contribution to the outlook that we claim to be true. In this sense we can present the history of ethics as a search for ethical truth.

In addition to the notion of the history of ethics as a common cognitive enterprise, there is a notion of history as a search for truth that is not incompatible with a proper sense of history. It is a picture of history that follows from the fact that we cannot understand the past unless we are prepared to evaluate its ethical significance to us, to our lives in the present. This picture does not in any way deny the fact that confrontation with past forms of life is purely notional. On the contrary, it is based on the recognition that the ethical inspiration of a past view need not necessarily lie in its effects on our actions or on the actual course of our lives. In other words, it does not disregard the distance that separates us from the past. Granted that the notion of truth, in this context, does not refer to the answer to an a-historical question, but to a particular point of view as it arises in studying the history of ethics, this interpretation of history does not picture outlooks of different periods as so many answers to the same ethical question, thereby obscuring the differences between concerns and issues that engage people in different ages. Nor does it, however, presuppose a standpoint that stands above history from which to appraise the history of ethics.

The foundation for this picture of the history of ethical views and practices as a search for truth is nothing but our ethical interest in the past, an interest that is an inevitable part of any interest in the history of ethics. ${ }^{51}$

\section{Katholieke Universiteit Leuven}

tim.heysse@hiw.kuleuven.be Xavier Vanmechelen and, in particular, Wilfried Goossens for comments on earlier versions. 